\title{
Nanostructured transition metal oxides obtained by SPVD
}

\author{
Adriana Gabriela Plăiașu ${ }^{1, *}$, Marian Cătălin Ducu ${ }^{1,2}$, Sorin Georgian Moga ${ }^{2}$, Aurelian Denis Negrea ${ }^{2}$, \\ and Ecaterina Magdalena Modan ${ }^{2}$ \\ ${ }^{1}$ University of Pitesti, Manufacturing and Industrial Management Department, 1, Târgul din Vale, Pitesti, Arges, Romania \\ ${ }^{2}$ University of Pitesti, Regional Center of Research \& Development for Materials, Processes and Innovative Products Dedicated \\ to the Automotive Industry (CRC\&D-Auto), University of Pitesti, 11, Doaga, Pitesti, Arges, Romania
}

Received: 5 December 2019 / Accepted: 8 February 2020

\begin{abstract}
The interest in the unique properties associated with materials having structures on a nanometer scale has been increasing at an exponential rate in last decade. Transition metal oxides are preferred materials for catalytic applications due to their half-filled d orbitals that make them exist in different oxidation states. Transition metal oxides show a broad structural variety due to their ability to form phases of varying metal to oxygen ratios reflecting multiple stable oxidation states of the metal ions. The Solar Physical Vapor Deposition (SPVD) presented in the paper as elaboration method is an original process to prepare nanopowders working under concentrated sunlight in $2 \mathrm{~kW}$ solar furnaces. The influence of the synthesis parameters on the chemical and microstructural characteristics of zinc and manganese oxides synthesized nanophases has been systematically studied using XRD, SEM and EDX.
\end{abstract}

Keywords: Nanostructured transition metal oxide / synthesis / solar energy / characterisation

\section{Introduction}

Substantial progress has been achieved in recent years in the development and characterisation of nanostructured materials, which have thus become available for a wide range of applications. In such materials it was noted that with the decrease in the size of the crystalit, the grain limits begin to substantially contribute to the microscopic properties of the material due mainly to segregation of impurities and dopants. The use of modern investigative methods (HREM, TEM, SEM, AFM, EXAFS, XRF) also highlighted that the structure and properties of nanomaterials depend on the method of obtaining, and the study of relations between nanostructure and properties. Nanotechnology have become an interdisciplinary area of great importance, with extraordinary development possibilities in the coming years. A current global task is the production of nanopulbers, thus opening the way for the exploitation of the effects produced by the transition to the nanodimensions. Such effects concern the modification of electronic and optical properties, thermodynamic balance, diffusion kinetics, interphasic effects, as a result of changes in energy bands and excitation energies. Since electronic excitation is responsible for optoelectronic properties, the

\footnotetext{
* e-mail: gabriela.plaiasu@upit.ro
}

experimental and theoretical studies of nanometric particles are essential for checking the proposed theories $[1,2]$.

Nanocrystalline oxide materials have been extensively studied in recent years due to the specific electrical, mechanical, physical properties due to the very high surface/volume ratio. They are part of the great category of technical ceramics, and functional ceramic with electronic and electrotechnical uses represents about $80 \%$ of the technical ceramics production. Metal oxide nanoparticles became significant constituents in applied nanotechnology for gas sensors, batteries, magnetic storage media, solar cells, catalysis, energy conversion, food, building, medicine, agriculture, cosmetics or textile. From the great variety of oxides transition metal oxides are preferred materials for catalytic applications due to their half-filled d orbitals that make them exist in different oxidation states [3]. It is well known that nanoceramics prepared by physical methods tend to quasiperfect crystals, while chemical synthesis leads to particles with surface and complex chemistry [4]. The solar physical vapor deposition or solar PVD (SPVD) is an original process to prepare nanopowders. Pure $\mathrm{ZnO}$, Zn1-xAlxO, Zn1-xCoxO, (Zn1-xBixO), Bi1-yZny)2O3 and metallic Zn nanophases have been prepared by this method.

The objectives of our research carried out on the elaboration and characterisation of nanostructured oxides developed by SPVD are: determination of the optimal 
parameters of solar energy development of nanostructured transition metal oxides (NTMO); determination of microstructural parameters for identified phases; determination of the morphology of the developed powders; determination of the influence of reaction conditions (solar flow and pressure) on crystalline dimensions; determination of the variation of the crystalite size according to the technological parameters; study of morphology and composition and establishing correlation technological parameters-composition-structure-morphology.

\section{State of the art regarding nanostructured transition metal oxides (NTMO)}

Cerium oxide nanoparticles have been produced using several different synthesis methods such as: sol-gel, thermal decomposition, solvothermal oxidation, microemulsion, pyrolysis, spray, hydrothermal synthesis [4-7]. In doped form cerium oxide is of interest to solid oxide fuel cells (SOFC) due to high conductivity of oxygen ions (oxygen atoms are moving unfrozen through them) at temperatures of $500-800^{\circ} \mathrm{C}$. The doped and undoped oxide exhibit high electronic conductivity. However doped cerium oxide has an enlarged electrolytic region (area with predominant ion conductivity), which allows its use as electrolyte in the SOFC. Replacing a fraction of the cerium oxide with gadolin is inserted the vacant oxygen into the crystal without adding the electrical load. This increase in ionic conductivity leads to a better electrolyte [7].

Between advanced ceramic materials, zirconium dioxide occupies an important place due to the complex of special thermo-mechanical and chemical resistance properties, in particular: high tenacity (reduced fragility), expressed by the tenacity module $\left(10-20 \mathrm{~m}^{1 / 2}\right)$ and hot superplastic deformation properties (deformation coefficients $300-800 \%$ at $1673-1723 \mathrm{~K}$ ), which will revolutionize the technologies of obtaining structural ceramic products. Also, zirconium dioxide is a basic material in functional ceramics with ionic conduction, used as solid electrolyte in the construction of oxygen sensors, gas purification devices or electric combustion cells. Obtaining optimal properties is conditional mainly on: the use of powders with controlled crystalline structure, monodispersed nanoparticles and nanocristallines; elaboration of advanced purity powders which avoid the apparition of fragilizing intergranular phases and control of nucleation mechanisms and processes of crystalites growing during compactization-sinterisation. For structural applications in obtaining ceramics with high tenacity and mechanical strength or with properties of superplasticity it is desirable to use partially stabilized $\mathrm{ZrO}_{2}$ (PSZ), consisting of a cubical matrix containing the fine tetragonal phase polycrystalline tetragonal $\mathrm{ZrO}_{2}$ (TZP). Cubic stabilized zirconium dioxide, especially with Ytriu, is the most common solid electrolyte because the material possesses an adequate level of conductivity of oxygen ions and is stable both in the oxidises and reducing atmosphere. In pure state $\mathrm{ZrO}_{2}$ is not the ionic conductor because of the monoclinical structure with very small ion conductivity (strictly covalent order of the network). By melting about $2680{ }^{\circ} \mathrm{C}$ but especially by using some quartzstructure oxides, the quartz crystalline phase (fluorine type) can be stabilised $[5,6]$.

Black copper oxide (II) is known as a thermal stable ptype semiconductor, with a gap of $1.2-1.9 \mathrm{eV}$, and considered to be an excellent candidate for long-term stable and low energy consuming devices. On the other hand, nanostructured copper oxide has captured the attention of researchers due to low-cost elaboration, as well as potential applications in various areas, such as catalysts, capacitors, other electrochemical, photovoltaic cells, nano-field emission devices and gas sensors. Indeed, particles, plates, thin films and $\mathrm{CuO}$ nanowires were manufactured for the detection of $\mathrm{CO}, \mathrm{NO}_{2}, \mathrm{H}_{2}$ and $\mathrm{H}_{2} \mathrm{~S}$ [8-13]. Depending on the gas detection mechanism, the adsorption/desorption process occurs on the surface, leading to the increase or reduction of electronal (type $n$ ) or vacancies (type $p$ ), which leads to increased performance of nanostructured sensors [16]. Current research has shown the use of $\mathrm{CuO}$ nanoparticles as adsorption of arsenic from contaminated waters. The synthesis methods used to obtain a nanostructured, in the form of wires, films, tubes or plates, were: sol-gel, precipitation, decomposition, deposition and hydrothermal synthesis [15].

A large number of manganese oxides are current due to various oxidation number of manganese (II-IV). Understanding the unique properties: magnetic, structural and transport of these oxides have attracted considerable interest in recent years. The most well known are: $\mathrm{MnO}, \mathrm{Mn}_{2} \mathrm{O}_{3}$ and $\mathrm{Mn}_{3} \mathrm{O}_{4}$, exhibit a wide range of applications in catalytic and accumulator technologies. Manganese oxide (II) provides a model for theoretical studies of electronic and magnetic properties of quartz-structure oxides. The magnetism of manganese oxide has attracted the attention of researchers because with the decrease in the dimension of crystallite, changes are produced. Antiferromagnetic, $\mathrm{MnO}$ is created by a first order transition to $117 \pm 1 \mathrm{~K}$ $\left(T_{N}\right)$, supplemented by a distortion of the cubic structure. Nanoparticles of $\mathrm{MnO}$ doped in the LiF matrix at low temperature caused a decrease of $T_{N}(85-73 \mathrm{~K})$ with a decreased size of $\mathrm{MnO}(3.7-5.4 \mathrm{~nm})$. The synthesis methods, used for the development of $\mathrm{MnO}$, in the form of nanoparticles or films, reported in literature are: precipitation, thermal decomposition, sol-gel method, electrodeposition and laser deposition $[14,17]$.

Many synthesis approaches, such as chemical solution precipitation, sol-gel method, microwave-assisted hydrothermal processes, mechano-chemical processing, polyvinyl pyrrolidone solution route, electrochemical synthesis, combustion method, direct sono-chemical route and gasliquid co-precipitation have been used for preparation of different oxides. Literature data have not yet revealed the elaboration of nanostructured cerium, zirconium, copper or manganese oxides by physical synthesis with solar energy. In this context the objectives of our research focus on the 

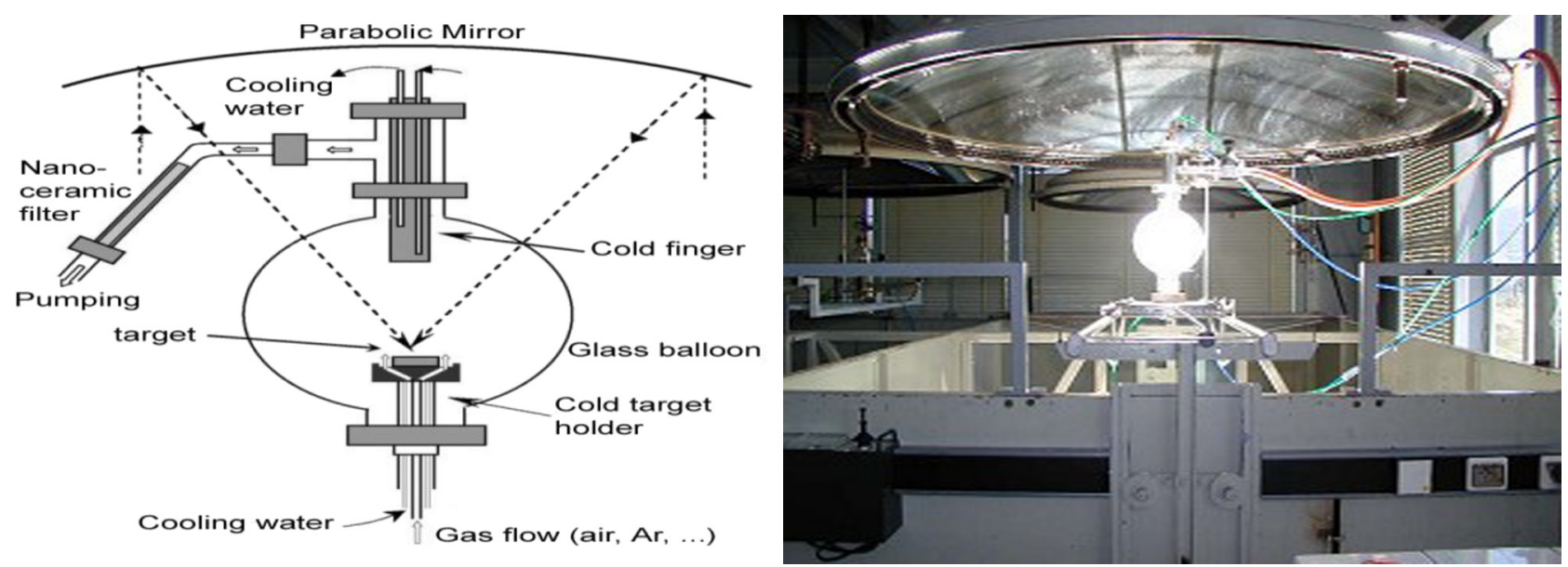

Fig. 1. (a) SPVD reactor schema; (b) SPVD in process.

Table 1. Parameters of elaboration process by SPVD.

\begin{tabular}{llll}
\hline $\begin{array}{l}\text { Precursors } \\
\text { (commercial powder) }\end{array}$ & $\begin{array}{l}\text { Synthesis } \\
\text { type }\end{array}$ & $\begin{array}{l}\text { Solar flux } \\
\text { density }\left(\mathrm{W} / \mathrm{m}^{2}\right)\end{array}$ & $\begin{array}{l}\text { Reactor pressure } \\
- \text { Ar (torr) }\end{array}$ \\
\hline $\mathrm{CeO}_{2}+10 \%$ mol Gd & SPVD & 935 & 70 \\
$\mathrm{ZrO}_{2}+10 \% \mathrm{~mol} \mathrm{Gd}$ & SPVD & 985 & 60 \\
$\mathrm{CuO}+10 \% \mathrm{~mol} \mathrm{Mn}$ & SPVD & 933 & 50 \\
$\mathrm{MnO}+1 \% \mathrm{~mol} \mathrm{Zr}$ & SPVD & 961 & 80 \\
\hline
\end{tabular}

elaboration and characterisation of nanostructured oxides developed by SPVD are: determination of the optimal parameters of solar energy development of nanostructured transition metal oxides (NTMO); determination of microstructural parameters for identified phases; determination of the morphology of the developed powders; determination of the influence of reaction conditions (solar flow and pressure) on crystalline dimensions; determination of the variation of the crystalite size according to the technological parameters; study of morphology and composition and establishing correlation technological parameters-composition-structure-morphology.

\section{Experimental studies}

\subsection{Synthesis of nanopowders by SPVD}

Synthesis by physical deposition in vapour phase using solar energy (SPVD) consists in evaporate a target in a reactor under solar radiation, in argon atmosphere as seen in Figure 1. The precursor commercial powder evaporates and condenses after continuously cooling on a nanoporous filter, from which can be collected.

The vapocondensation parameters characteristic for SPVD is presented in Table 1. The solar flux varies depending the sunny conditions.

\subsection{Morphological characterization}

The morphological characterization of solar physical vapodeposed nanopowders (SPVD oxides) was performed by Scanning Electron Microscopy (SEM). Phase distribution and the formation of shell structure was analyzed by SEM-EDX method using a TESCAN Vega II LMU unit and a Hitachi 8230 equipment. SEM is suitable because can permit an image of a sample by surface scanning with a monokinetic and very fine electron beam. The various interactions that occur at the surface of the sample are transformed by the detector into a signal which is taken over by a cathode ray screen whose scanning is synchronized with that of the electron beam.

From the morphological analysis it can be observed the powder has agglomerations and the shape form spheres type for Gd-doped SPVD cerium oxide and Gd-doped SPVD zirconium oxide as seen in Figures $2 \mathrm{a}$ and $3 \mathrm{a}$. In the case of Mn-doped SPVD cooped oxide and Zr-doped SPVD manganese oxide as seen in Figures $4 \mathrm{a}$ and $5 \mathrm{a}$ the particle shape form is hexagonal, tube and sphere and the powders are dispersed. The EDX analysis from Figures $2 \mathrm{~b}$ and $3 \mathrm{~b}$ performed shows the presence of dopant element such as: $\mathrm{Gd}$ in the case of SPVD cerium oxide, and from Figures 4b and $5 \mathrm{~b}$ relives the presence of $\mathrm{Mn}$ and $\mathrm{Zr}$. Considering that 


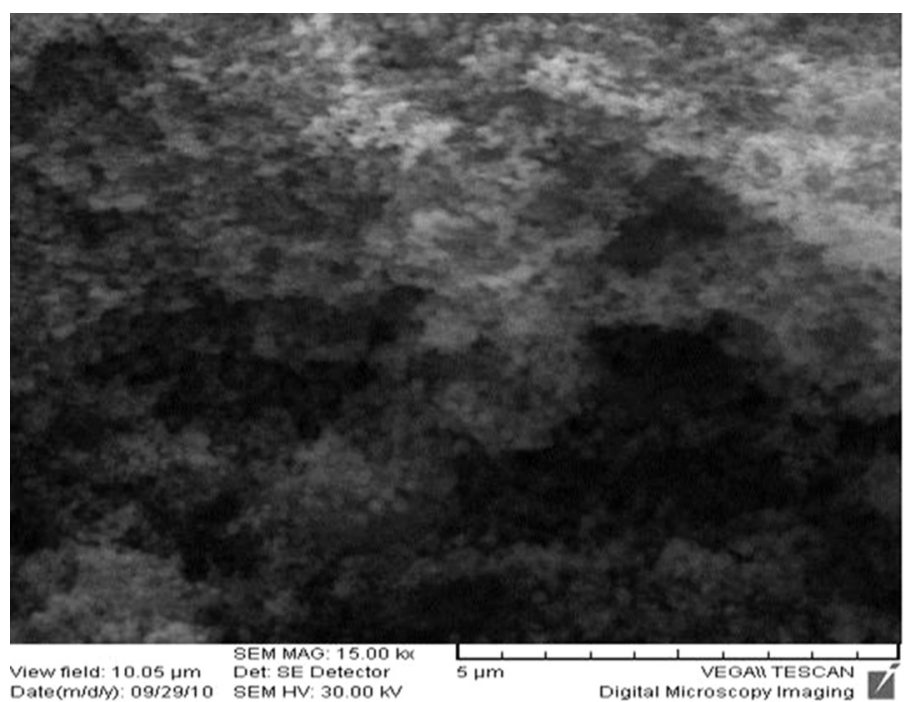

(a)

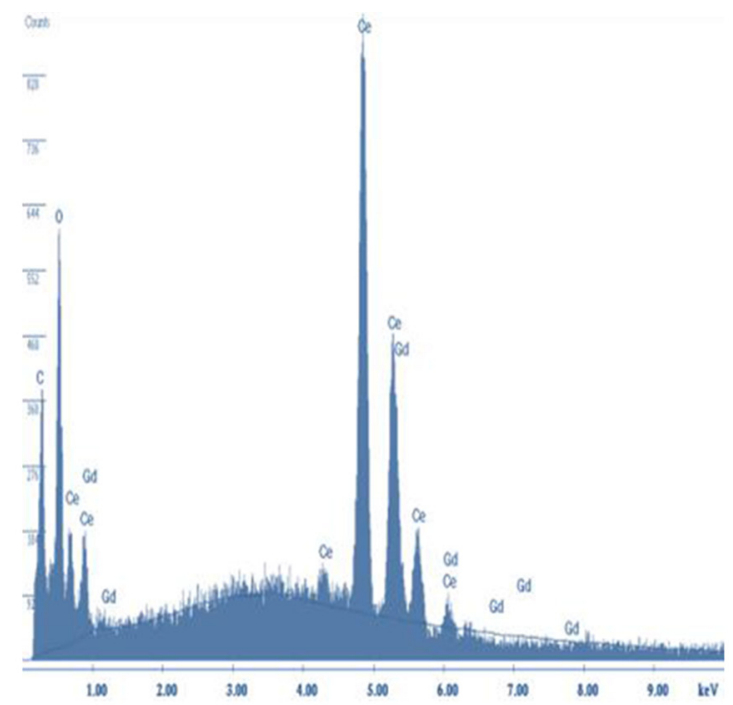

(b)

Fig. 2. (a) SEM micrograph of nano-SPVD powders of $\mathrm{CeO}_{2}$ doped with Gd. (b) EDX spectrum of nano-SPVD powders of CeO 2 doped with Gd.

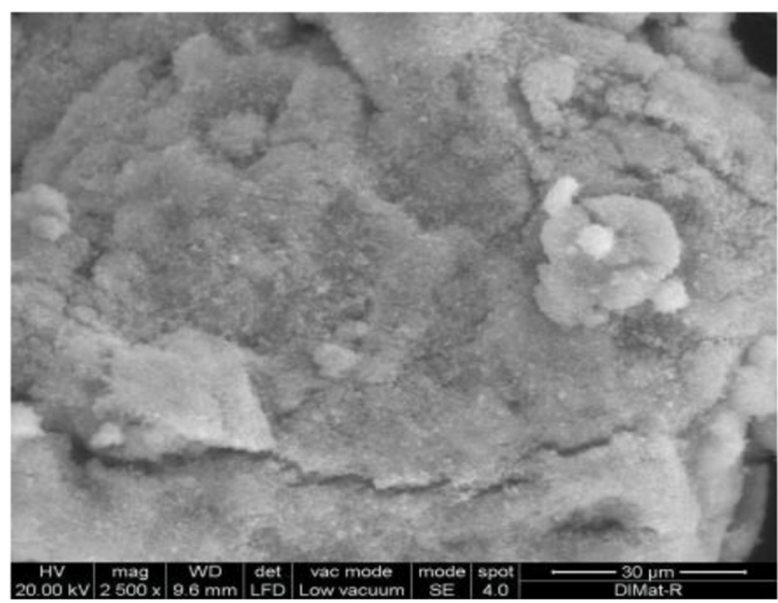

(a)

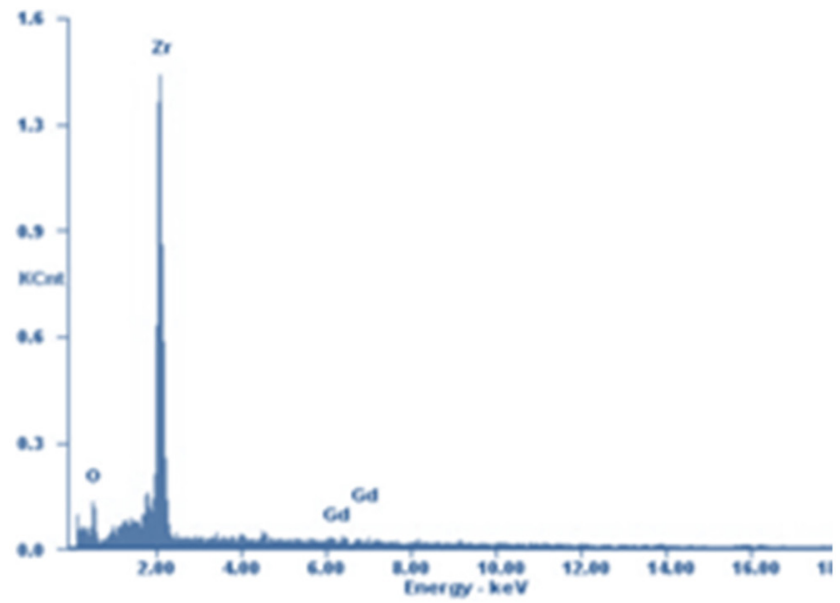

(b)

Fig. 3. (a) SEM micrograph of nano-SPVD powders of $\mathrm{ZrO}_{2}$ doped with Gd. (b) EDX spectrum of nano-SPVD powders of $\mathrm{ZrO} \mathrm{S}_{2}$ doped with Gd.

Table 2. Experimental results from characterization of oxide nanoparticles.

\begin{tabular}{llll}
\hline $\begin{array}{l}\text { Precursors } \\
\text { (commercial powder) }\end{array}$ & $\begin{array}{l}\text { Type of } \\
\text { synthesis }\end{array}$ & $\begin{array}{l}\text { Average particle } \\
\text { size (nm) }\end{array}$ & Shape \\
\hline $\mathrm{CeO}_{2}+10 \% \mathrm{~mol} \mathrm{Gd}$ & SPVD & $245-450$ & Spheres \\
$\mathrm{ZrO}_{2}+10 \% \mathrm{~mol} \mathrm{Gd}$ & SPVD & $130-221$ & Spheres \\
$\mathrm{CuO}+10 \% \mathrm{~mol} \mathrm{Mn}$ & SPVD & $38-46$ & Hexagons \\
$\mathrm{MnO}+10 \% \mathrm{~mol} \mathrm{Zr}$ & SPVD & 58 & Tubes, hexagons, spheres \\
\hline
\end{tabular}

from the elemental chemical analysis it is observed that the powder contains gadolinium, which shows that doping was done properly under the given reaction conditions.

All, the identified particles present dimensions between 38 and $450 \mathrm{~nm}$, the size analysis was used
ImageJ software. The data obtained are summarized in Table 2.

The phase composition was analyzed by XRD with the help of Rigaku Ultimate IV equipment by the BragBrentano method, using the $\mathrm{CuK} \alpha$ source $\lambda=1.54 \AA$. The 


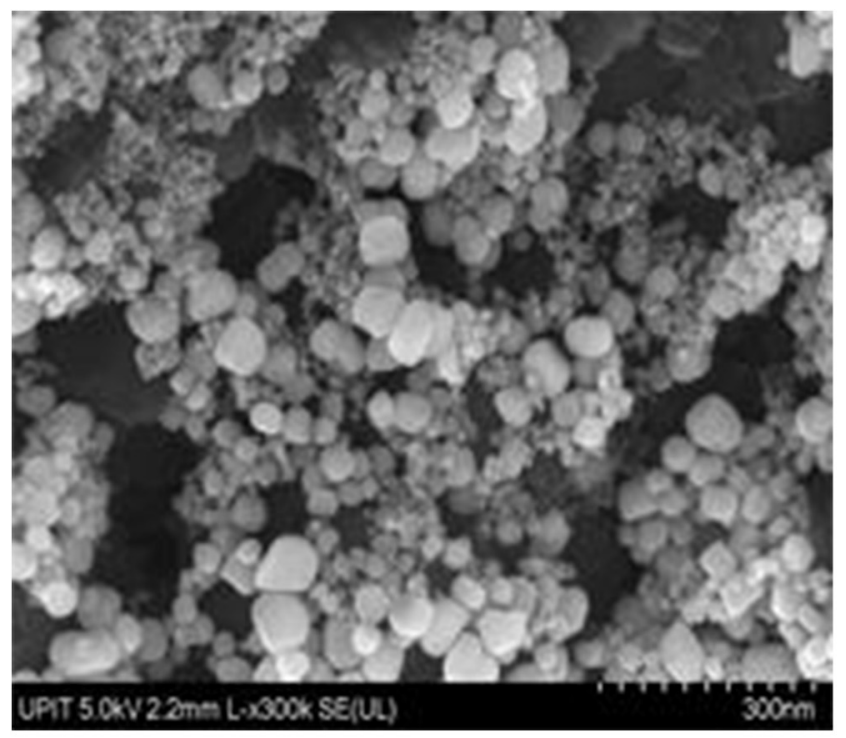

(a)

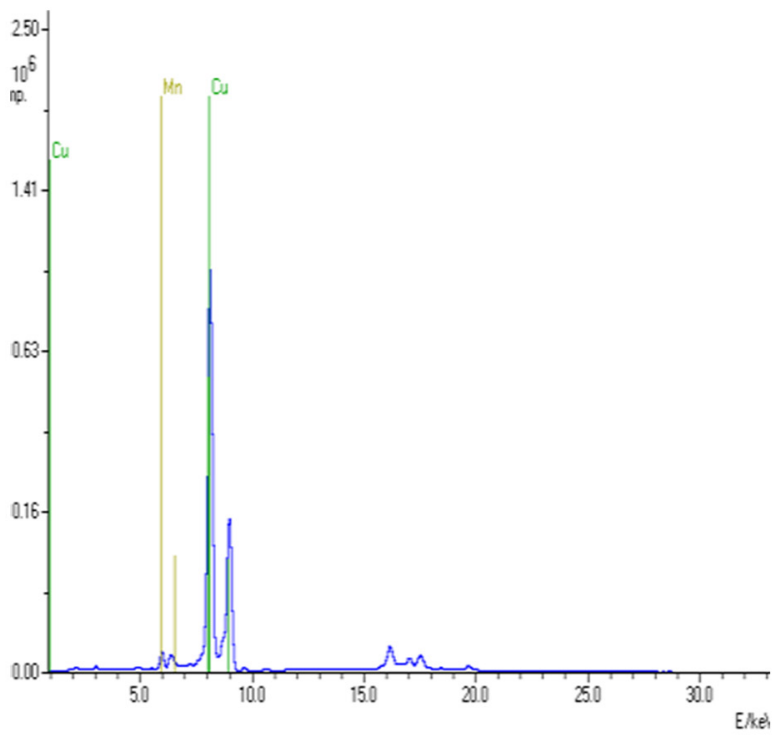

(b)

Fig. 4. (a) SEM micrograph of nano-SPVD powders of CuO doped with Mn. (b) EDX spectrum of nano-SPVD powders of CuO doped with Mn.

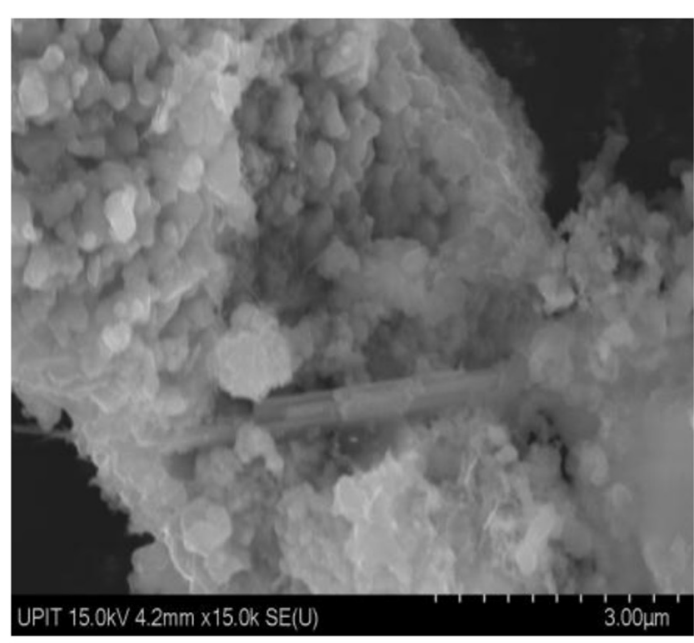

(a)

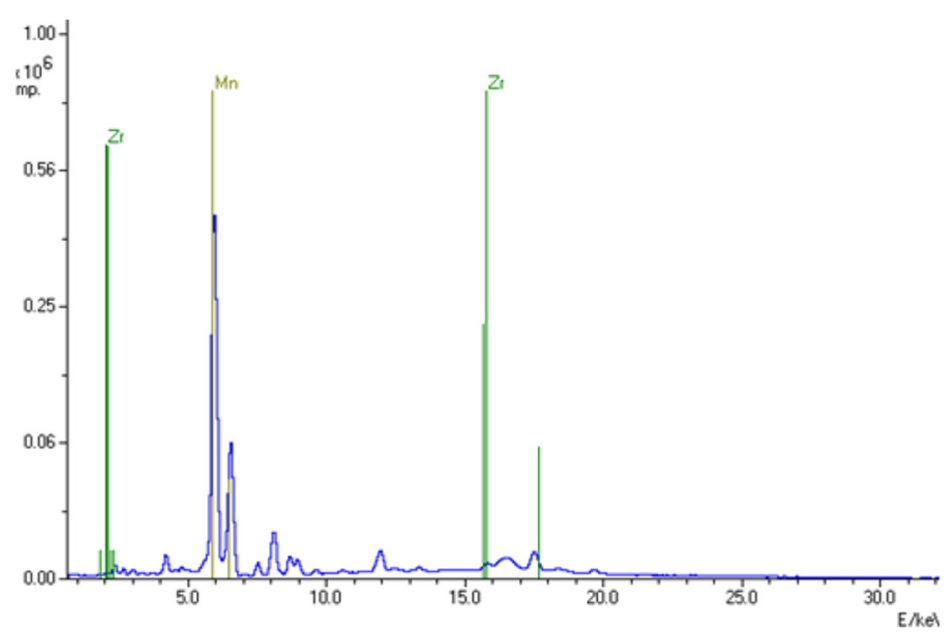

(b)

Fig. 5. (a) SEM micrograph of nano-SPVD powders of MnO doped with Zr. (b) EDX spectrum of nano-SPVD powders of MnO doped with $\mathrm{Zr}$.

XRD results show that the obtained powders are single phase with the cubic structure in the case of nano-SPVD Gd-doped cerium oxide powders, as seen in Figure 6, and tetragonal phase in the case of nano-SPVD Gd-doped zirconium oxide powders, as seen in Figure 7.

Due to reaction condition in the case of $\mathrm{Mn}$-doped cooper oxide (Fig. 8) and Zr-doped manganese oxide SPVD-powders (Fig. 9) was obtained a mixture of phases corresponding to oxidation number of transition metal. The XRD results regarding the average crystallite size using Sherrer equation and phase analysis are summarized in Table 3.
The presence of the $\mathrm{Mn}_{3} \mathrm{O}_{4}$ phase in XRD patterns of Mn-doped cooper oxide indicates an oxidation during the vaporization reaction followed by condensation, which cannot be controlled under solar flux as seen in Figure 8. Also the XRD patterns for Zr-doped manganese oxide after SPVD process releave the presence of manganese oxide corresponding of different oxidation number of Mn. The presence of zirconium oxide phase denotes a process of doping that is difficult to control under the action of solar energy. However, the small size of the crystallites is difficult to obtain by the chemical methods which makes the SPVD technique a good candidate for obtaining nanopowders. 


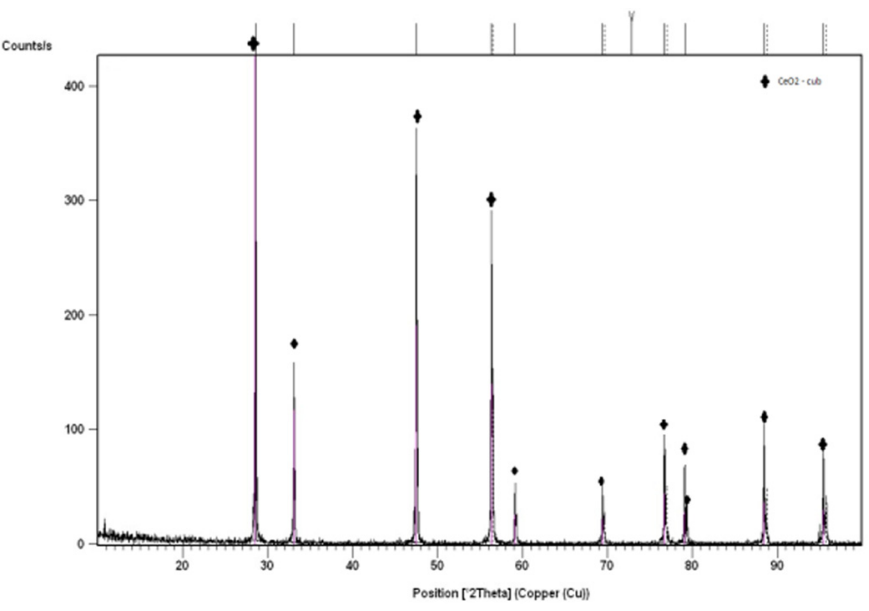

Fig. 6. XRD patterns of nano-SPVD powders of $\mathrm{CeO}_{2}$ doped with Gd.

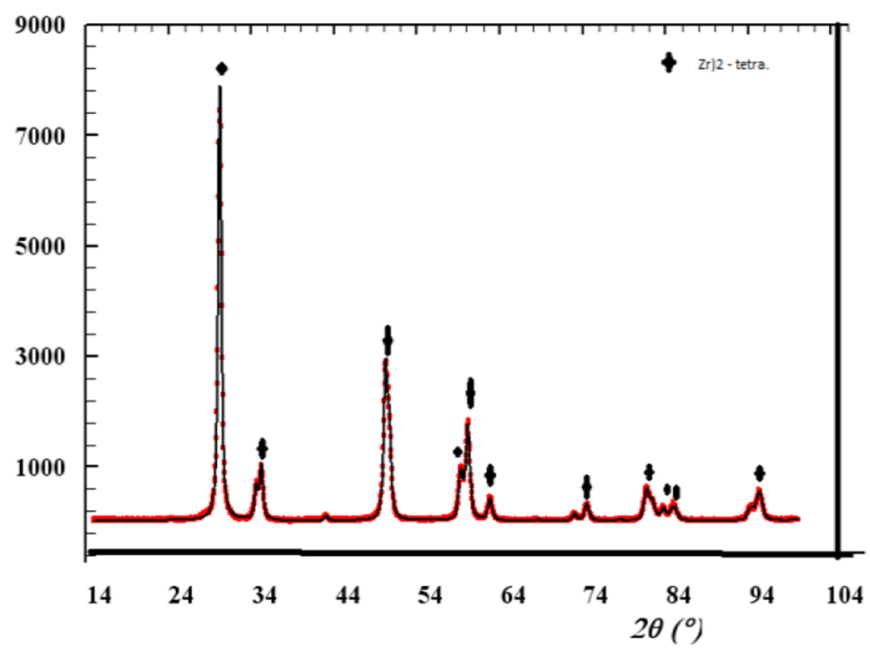

Fig. 7. XRD patterns of nano-SPVD powders of $\mathrm{ZrO}_{2}$ doped with Gd.

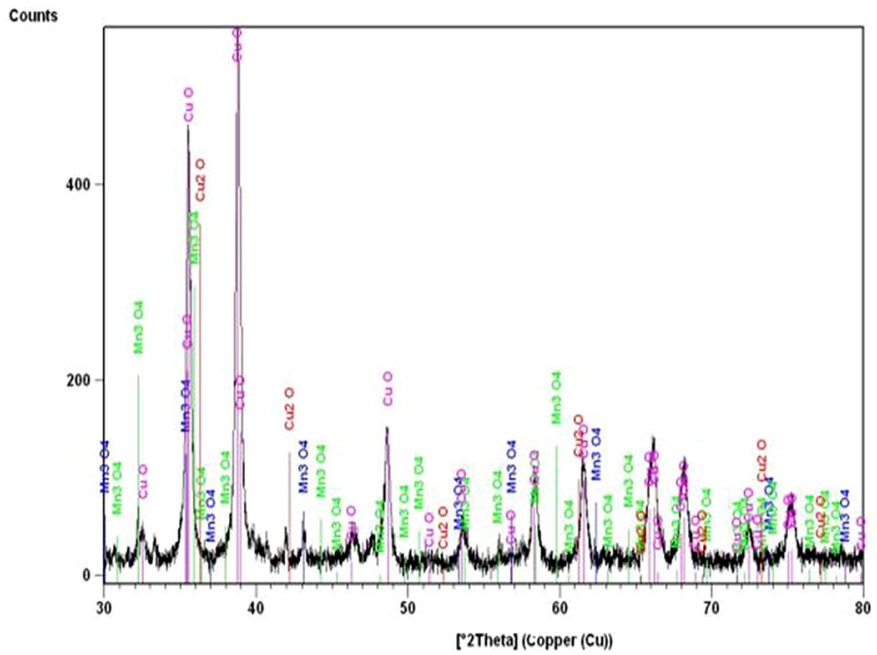

Fig. 8. XRD patterns of nano-SPVD powders of $\mathrm{CuO}$ doped with $\mathrm{Mn}$.

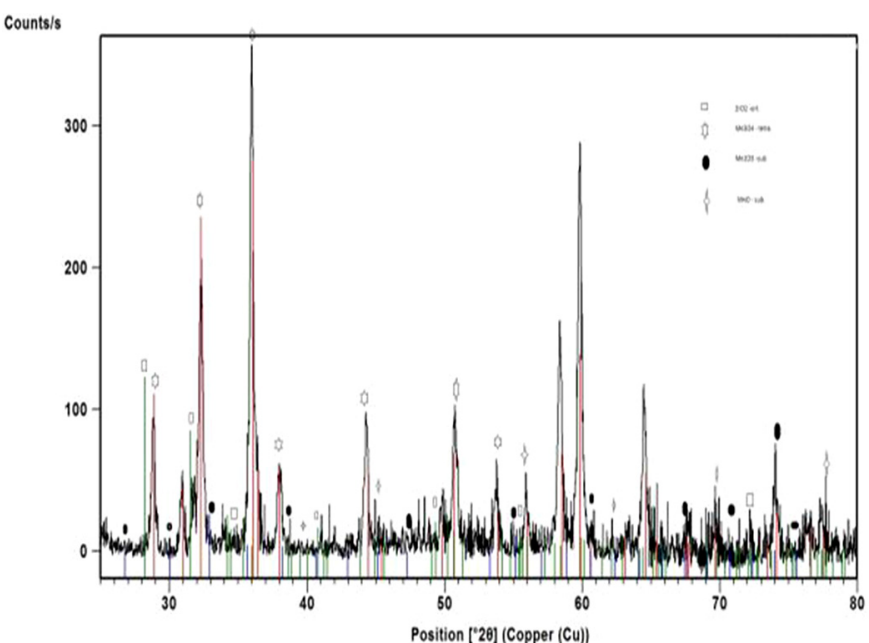

Fig. 9. XRD patterns of nano-SPVD powders of MnO doped with $\mathrm{Zr}$.

Table 3. XRD results.

\begin{tabular}{lll}
\hline SPVD powders & $\begin{array}{l}\text { Average } \\
\text { crystallite } \\
\text { size }(\mathrm{nm}) \\
\text { from XRD }\end{array}$ & \\
\hline $\mathrm{CeO}_{2}+10 \% \mathrm{~mol} \mathrm{Gd}$ & 72.33 & $\mathrm{CeO}_{2}$ cub. \\
$\mathrm{ZrO}_{2}+10 \% \mathrm{~mol} \mathrm{Gd}$ & 11.38 & $\begin{array}{l}\mathrm{ZrO}_{2} \text { tetra. } \\
\mathrm{CuO} \text { mono }\end{array}$ \\
$\mathrm{CuO}+10 \% \mathrm{~mol} \mathrm{Mn}$ & 30.94 & $\mathrm{Cu}_{2} \mathrm{O}$ cub. \\
& & $\mathrm{Mn}_{3} \mathrm{O}_{4}$ tetr. \\
& & $\mathrm{Mn}_{2} \mathrm{O}_{3}$ cub. \\
& $\mathrm{Mn}_{3} \mathrm{O}_{4}$ tetr. \\
& $\mathrm{MnO}$ cub. & $\mathrm{ZrO}_{2}$ ort. \\
\hline $\mathrm{MnO}+1 \%$ mol $\mathrm{Zr}$ & 55.23 & \\
& &
\end{tabular}

\section{Conclusions}

After considering some trends to define what are a nanopowder and a nanomaterial, an original process to prepare nanopowders: the Solar Physical Vapor Deposition or Solar PVD (SPVD) is presented in the paper. It may be concluded that physical synthesis using solar energy demonstrates to be an efficient method for obtaining nanostructured oxides starting from commercially, easy to procure. The morfo-structural characterization using SEM coupled with EDX and XRD are appropriate for a complete description of SPVD doped NTMO nanopowders. The influence of reaction conditions determined the dopping process and the mixture of oxides for different oxide states. The proposed method for synthesis using solar energy proves to be an ecological and innovative way of obtaining nanostructured metal transition oxides. The SPVD powders with average crystallite size between 11 and $70 \mathrm{~nm}$ can be 
utilised in future applications for films elaboration, catalyst or electronic devices. The mixture of oxides appears to be promising materials for applications such as preparing a new solid electrolyte for SOFC. The few examples presented here focus the interest of SPVD methods to strength on nanopowders; but it still remains to discover the best way of implementing them in the applications at large scale. Nevertheless, new investigations are needed.

The authors are grateful to SFERA, 7th EU Program, grant no. 228296, which has provided opportunities to collaborate with researchers from France working with the solar facilities. This work was supported by a grant of the Romanian Minister of Research and Innovation - UEFISCDI, project number PN-IIIP1-1.2-FPRD-2017-0755, Advanced materials and laser/plasma processing technologies for energy and depollution: growth of applicative potential and scientific interconnectivity in the field of eco-nanotechnologies - MALASENT.

\section{References}

1. J. Cinthia, G. Sudha Priyanga, R. Rajeswarapalanichamy, K. Iyakutti, Structural, electronic and mechanical properties of alkaline earth metal oxides $\mathrm{MO}\left(\mathrm{M} \frac{1}{4} \mathrm{Be}, \mathrm{Mg}, \mathrm{Ca}, \mathrm{Sr}, \mathrm{Ba}\right), \mathrm{J}$. Phys. Chem. Solids 79 (2015) 23-42

2. T. Jõgiaas, R. Zabels, A. Tamm, M. Merisalu, I. Hussainova, M. Heikkilä, H. Mändar, K. Kukli, M. Ritala, M. Leskelä, Mechanical properties of aluminum, zirconium, hafnium and tantalum oxides and their nanolaminates grown by atomic layer deposition, Surf. Coatings Technol. 282 (2015) 36-42

3. E.N. Karasinski, M.G. Da Luz, C.M. Lepienski, L.A.F. Coelho, Nanostructured coating based on epoxy/metal oxides: Kinetic curing and mechanical properties, Thermochim. Acta 569 (2013) 167-176

4. S. Zeng, Y. Wang, K. Liu, F. Liu, H. Su, $\mathrm{CeO}_{2}$ nanoparticles supported on $\mathrm{CuO}$ with petal-like and sphere-flower morphologies for preferential CO oxidation, Int. J. Hydrogen Energy 37 (2012) 11640-11649

5. R. Vacassy, C. Guizard, V. Thoraval, L. Cot, Synthesis and characterization of microporous zirconia powders: application in nanofilters and nanofiltration characteristics, J. Memb. Sci. 132 (1997) 109-118

6. D.A. Neumayer, E. Cartier, Materials characterization of $\mathrm{ZrO}_{2}-\mathrm{SiO}_{2}$ and $\mathrm{HfO}_{2}-\mathrm{SiO}_{2}$ binary oxides deposited by chemical solution deposition, J. Appl. Phys. 90 (2001) 1801-1808

7. G. Petot-Ervas, C. Petot, D. Zientara, J. Kusinski, Microstructure and transport properties of Y-doped zirconia and Gd-doped ceria, Mater. Chem. Phys. 81 (2003) 305-307

8. J.S.K. Arockiasamy, J. Irudayaraj, Natural dye sensitized $\mathrm{CuO}$ nanorods for luminescence applications, Ceram. Int. 42 (2016) 6198-6205

9. R.S. Bhalerao-Panajkar, M.M. Shirolkar, R. Das, T. Maity, P. Poddar, S.K. Kulkarni, Investigations of magnetic and dielectric properties of cupric oxide nanoparticles, Solid State Commun. 151 (2011) 55-60

10. S. Dek, P.A. Joy, Synthesis and magnetic properties of Mn doped $\mathrm{ZnO}$ nanowires, Solid State Commun. 142 (2007) 190-194

11. V. Dhanasekaran, T. Mahalingam, Physical properties evaluation of various substrates coated cupric oxide thin films by dip method, J. Alloys Compd. 539 (2012) 50-56

12. V. Dhanasekaran, T. Mahalingam, R. Chandramohan, J.-K. Rhee, J.P. Chu, Electrochemical deposition and characterization of cupric oxide thin films, Thin Solid Films 520 (2012) 6608-6613

13. L.D. Duc, D.T.T. Le, N. Van Duy, N.D. Hoa, N. Van Hieu, Single crystal cupric oxide nanowires: Length- and densitycontrolled growth and gas-sensing characteristics, Physics E 58 (2014) 16-23

14. W. Gac, G. Słowik, W. Zawadzki, Structural and surface changes of copper modified manganese oxides, Appl. Surf. Sci. 370 (2016) 536-544

15. P.K. Goswami Raul, M.K. Purkait, Arsenic adsorption using copper (II) oxide nanoparticles, Chem. Eng. Res. Des. 90 (2012) 1387-1396

16. N.D. Hoa, S.Y. An, N.Q. Dung, N. Van Quy, D. Kim, Synthesis of p-type semiconducting cupric oxide thin films and their application to hydrogen detection, Sens. Actuat. B 146 (2010) 239-244

17. A.G. Plăiașu, Sinteza și caracterizarea morfo-structurală a unor oxizi metalici nanostructurați, University Press, Pitesti, 2018

Cite this article as: Adriana Gabriela Plăiașu, Marian Cătălin Ducu, Sorin Georgian Moga, Aurelian Denis Negrea, Ecaterina Magdalena Modan, Nanostructured transition metal oxides obtained by SPVD, Manufacturing Rev. 7, 12 (2020) 